\title{
Genetic Analysis of Diversity within a Chinese Local Sugarcane Germplasm Based on Start Codon Targeted Polymorphism
}

\author{
Youxiong Que, ${ }^{1}$ Yongbao Pan, ${ }^{2}$ Yunhai Lu, ${ }^{1}$ Cui Yang, ${ }^{1}$ Yuting Yang, \\ Ning Huang, ${ }^{1}$ and Liping $\mathrm{Xu}^{1}$ \\ ${ }^{1}$ Key Laboratory of Sugarcane Biology and Genetic Breeding, Ministry of Agriculture/Fujian Agriculture and Forestry University \\ Fuzhou 350002, China \\ ${ }^{2}$ USDA-ARS, Sugarcane Research Laboratory, Houma, LA 70360, USA
}

Correspondence should be addressed to Youxiong Que; queyouxiong@hotmail.com and Liping Xu; xlpmail@126.com

Received 4 November 2013; Revised 14 December 2013; Accepted 3 January 2014; Published 24 March 2014

Academic Editor: Guihua H. Bai

Copyright (C) 2014 Youxiong Que et al. This is an open access article distributed under the Creative Commons Attribution License, which permits unrestricted use, distribution, and reproduction in any medium, provided the original work is properly cited.

\begin{abstract}
In-depth information on sugarcane germplasm is the basis for its conservation and utilization. Data on sugarcane molecular markers are limited for the Chinese sugarcane germplasm collections. In the present study, 20 start codon targeted (SCoT) marker primers were designed to assess the genetic diversity among 107 sugarcane accessions within a local sugarcane germplasm collection. These primers amplified 176 DNA fragments, of which 163 were polymorphic (92.85\%). Polymorphic information content (PIC) values ranged from 0.783 to 0.907 with a mean of 0.861 . Unweighted pair group method of arithmetic averages (UPGMA) cluster analysis of the SCoT marker data divided the 107 sugarcane accessions into six clusters at 0.674 genetic similarity coefficient level. Relatively abundant genetic diversity was observed among ROC22, ROC16, and ROC10, which occupied about $80 \%$ of the total sugarcane acreage in China, indicating their potential breeding value on Mainland China. Principal component analysis (PCA) partitioned the 107 sugarcane accessions into two major groups, the Domestic Group and the Foreign Introduction Group. Each group was further divided based on institutions, where the sugarcane accessions were originally developed. The knowledge of genetic diversity among the local sugarcane germplasm provided foundation data for managing sugarcane germplasm, including construction of a core collection and regional variety distribution and subrogation.
\end{abstract}

\section{Introduction}

Sugarcane (Saccharum spp.) is the most important sugar crop in China by producing more than $90 \%$ of the total consumable sugar $[1,2]$. Sugarcane is also an important energy source as an herbaceous plant. It was reported that genetic improvement of sugarcane accounted for $75 \%$ of the yield increase in Hawaiian sugar industry in the 1950s and $>60 \%$ yield increase on Mainland China in recent decades $[1,3]$. According to the heterosis theory, parental lines with larger genetic distance values must be selected for crossing during cultivar development on the premise that the main attributes of the parental lines are complementary [4-6]. Evaluation of sugarcane germplasm with DNA markers helps understand the extent of genetic diversity among parental lines and the difference in genetic background among accessions. The knowledge on phylogenetic relationship among accessions of sugarcane germplasm collection will guide parental selection for the development of new cultivars [1, 5-7]. Therefore, genetic diversity analysis of sugarcane germplasm is important to the success of sugarcane breeding.

Modern sugarcane cultivars (Saccharum spp. hybrids) are interspecific hybrids among three to four Saccharum species. The Saccharum genus consists of six species: two wild, S. spontaneum and S. robustum, and four cultivated, S. officinarum, $S$. barberi, S. sinense, and S. edule [8]. Although morphological traits can be used to assess genetic diversity, these traits are strongly influenced by the environment and may show limited variation within species $[9,10]$. Molecular markers are therefore more suitable for the assessment of genetic diversity within a sugarcane germplasm collection. Since the last two decades of the 20th century, different molecular markers, 
including restriction fragment length polymorphism (RFLP) [11-13], 5S rRNA ITS marker [14, 15], random amplified polymorphic DNA (RAPD) [8, 16-18], intersimple sequence repeat (ISSR) $[19,20]$, amplified fragment length polymorphism (AFLP) [20-23], sequence-related amplified polymorphism (SRAP) [24], target region amplified polymorphism (TRAP) [25], single nucleotide polymorphism (SNP) [26], genomic simple sequence repeat (gSSR) [27-30], and ESTderived simple sequence repeats (EST-SSRs) [28, 29, 31], have been used in sugarcane germplasm evaluation and characterization.

More recently, Collard and Mackill [32] developed another DNA marker in rice, the start codon targeted (SCOT) marker, based on the short conserved nucleotide sequence that flanks the start codon ATG. Similar to RAPD and ISSR, SCoT marker involves a single oligonucleotide primer and is PCR based. However, due to the simultaneous binding of the primer on both DNA strands, the sequence between the two binding sites is amplified. As a relatively new marker technique, the SCoT marker has the following advantages: simple, low-cost, highly polymorphic, gene-targeted, and abundant in the genome. It has been utilized on different plant species, including rice [32], longan [33], grape [34], potato [35], orange [36], mango [37-39], peanut [40], and Cicer [41]. The objective of the present study was to explore the potential utility of the SCoT marker technique in assessing the genetic diversity and phylogenetic relationship within a local sugarcane germplasm collection.

\section{Materials and Methods}

2.1. Sugarcane Accessions within a Local Sugarcane Germplasm Collection. One hundred and seven sugarcane accessions from a local sugarcane germplasm collection were involved in the study (Table 1). The collection had been maintained in a sugarcane garden plot at the Sugarcane Research Institute, Fujian Agriculture and Forestry University, Fuzhou, China. Six accessions, namely, ROC10, ROC16, ROC20, ROC22, ROC25, and FN11, were leading sugarcane cultivars in China. Twenty-two accessions, namely, MT86-05, YG16, YG24, YG26, YT96-853, YZ03-194, YZ03-332, MT95-261, MT961027, MT96-6016, GT86-267, FN16, FN39, FN02-5707, FN981103, FN99-20169, FN04-2816, FN04-3504, CP89-1509, CZ19, RB72-454, and FR93-244, were recently released under the National Sugarcane Yield Trials Program in China. Four accessions, namely, GT97-40, FN15, YG18, and FN02-3924, were newly released based on the first and second cycles of varietal demonstrations under the Chinese National Sugarcane Industry Technology System.

2.2. SCoT Primers. Forty SCoT primers of 18 nucleotides each were designed based on the short conserved nucleotide sequence flanking the start codon ATG. The conserved sequence had the "ATG" codon fixed at positions $+1,+2$, and +3 , "G" at position +4 , "C" at position +5 , and "A," "C," and " $C$ " at positions $+7,+8$, and +9 , respectively. The primers differed from one another by at least one nucleotide at other positions, with an emphasis on variations at the $3^{\prime}$ end, which allowed specific annealing and amplification events to occur
[42]. The 40 SCoT primers were initially evaluated for PCR robustness on two sugarcane accessions, ROC22 and FN023504 .

2.3. Extraction of Sugarcane Genomic DNA. Leaf samples were collected from the top visible dewlap leave blade of each accession without any disease symptom. The Biospin plant genomic DNA extraction kit (Bioer Technology CO., Ltd., Hangzhou, China) was used to extract the genomic DNA from sugarcane leaf tissue. Both agarose gel electrophoresis and ultraviolet spectrophotometer were used to estimate quality and quantity of DNA samples.

2.4. SCoT-PCR Amplification and Detection. SCoT-PCR reaction volume was $25 \mu \mathrm{L}$, containing $1.5 \mu \mathrm{L}$ of template DNA $(25 \mathrm{ng} / \mu \mathrm{L}), 1.0 \mu \mathrm{L}$ primer at $10 \mu \mathrm{M}, 2.0 \mu \mathrm{L}$ dNTPs at $10 \mu \mathrm{M}, 0.125 \mu \mathrm{L}$ Taq DNA polymerase at $5 \mathrm{U} / \mu \mathrm{L}, 2.5 \mu \mathrm{L} 10 \mathrm{X}$ PCR buffer, and $17.875 \mu \mathrm{L}$ dd $\mathrm{H}_{2} \mathrm{O}$. SCoT-PCR was performed on an Eppendorf Mastercycler (Westbury, New York, USA). Initial denaturation was carried out at $94^{\circ} \mathrm{C}$ for $5 \mathrm{~min}$, followed by $35 \mathrm{cycles}$ of $94^{\circ} \mathrm{C}$ for $1 \mathrm{~min}, 51^{\circ} \mathrm{C}$ for $1 \mathrm{~min}, 72^{\circ} \mathrm{C}$ for $2 \mathrm{~min}$, and final extension at $72^{\circ} \mathrm{C}$ for $5 \mathrm{~min}$. The amplification products were separated in $1.2 \%$ agarose gels containing $0.5 \mu \mathrm{g} / \mathrm{mL}$ of ethidium bromide through electrophoresis in 1X TBE buffer solution at $5 \mathrm{~V} / \mathrm{cm}$ and visualized under a UVP ultraviolet transilluminator (Spring Scientific, New York, USA).

2.5. Statistical Analysis. PCR products were scored visually. To minimize errors, only clearly distinguishable bands were scored. Presence of a band was recorded as " 1 " and absence of a band was recorded as "0". Polymorphism information content (PIC) is a property value of a marker based on its allelic number and distribution frequency in a population. PIC for marker $i$ was calculated using PIC $=1-\sum P i^{2}$ according to Botstein et al. [43], where $P i$ is the allele frequency at locus $i$. Percentage of polymorphic bands (PPB), number of observed alleles $(\mathrm{Na})$, number of effective alleles $(\mathrm{Ne})$, Nei's genetic diversity index $(h)$, Shannon's information index $(I)$, total genetic diversity index $(H t)$, genetic diversity index within series $(H s)$, coefficient of genetic differentiation $\left(G_{s t}\right)$, and gene flow $\left(N_{m}\right)$ were calculated using POPGENE 1.31 [44]. Unweighted pair group method of arithmetic averages (UPGMA) was used for cluster analysis using NTSYSpc [45]. Principal component analysis (PCA) was conducted using a Dcenter module $[45,46]$.

\section{Results}

3.1. SCoT Polymorphism in Sugarcane. Upon initial evaluation, only 20 out of the 40 designed SCoT primers were able to prime amplification of DNA fragments. Nucleotide sequence and GC content of the 20 SCoT primers are listed in Table 2. The 20 SCoT primers amplified a total of 176 DNA fragments from the 107 sugarcane accessions, with 5 to 11 fragments per primer. Of the 176 fragments amplified, 163 were polymorphic. Primers P1, P29, and P31 amplified the highest number of DNA fragments, with an average of 11 DNA fragments per 
TABLE 1: Description of 107 sugarcane accessions from a local sugarcane germplasm collection.

\begin{tabular}{|c|c|c|c|c|c|c|c|}
\hline Code & Series & Accession & $\begin{array}{l}\text { Institute/country } \\
\text { Collection place }\end{array}$ & Code & Series & Accession & Institute/country \\
\hline 1 & $\mathrm{Q}$ & FY0901 & Australia & 55 & FN & FN05-2848 & FAFUSRI/China \\
\hline 2 & Q & FY0902 & Australia & 56 & FN & FN02-5707 & FAFUSRI/China \\
\hline 3 & $\mathrm{Q}$ & FY0903 & Australia & 57 & FN & FN98-1103 & FAFUSRI/China \\
\hline 4 & Q & FY0906 & Australia & 58 & FN & GZ1 & FAFUSRI/China \\
\hline 5 & Q & FY0907 & Australia & 59 & YC & YC71-374 & GZSRI/China \\
\hline 6 & Q & FY0908 & Australia & 60 & YC & YC73-512 & GZSRI/China \\
\hline 7 & Q & FY0909 & Australia & 61 & YC & YC80-125 & GZSRI/China \\
\hline 8 & Q & FY0910 & Australia & 62 & YC & YC82-96 & GZSRI/China \\
\hline 9 & Q & FY0911 & Australia & 63 & $\mathrm{YC}$ & YC89-35 & GZSRI/China \\
\hline 10 & Q & Q138 & Australia & 64 & YC & YC90-3 & GZSRI/China \\
\hline 11 & Q & Q190 & Australia & 65 & YC & YC90-33 & GZSRI/China \\
\hline 12 & Q & Q208 & Australia & 66 & YC & YC96-66 & GZSRI/China \\
\hline 13 & Q & FY0912 & Australia & 67 & $\mathrm{CP}$ & СР 67-412 & USA \\
\hline 14 & Q & FY0913 & Australia & 68 & $\mathrm{CP}$ & СР 33-310 & USA \\
\hline 15 & Q & FY0914 & Australia & 69 & $\mathrm{CP}$ & СР 34-120 & USA \\
\hline 16 & Q & FY0915 & Australia & 70 & $\mathrm{CP}$ & СР 49-50 & USA \\
\hline 17 & Q & FY0916 & Australia & 71 & $\mathrm{CP}$ & СР 64-412 & USA \\
\hline 18 & $\mathrm{Q}$ & FY0917 & Australia & 72 & $\mathrm{CP}$ & СР 65-357 & USA \\
\hline 19 & Others & H 56-752 & Hawaii/USA & 73 & $\mathrm{CP}$ & СР 72-1210 & USA \\
\hline 20 & Brazil & CI-2003 & Brazil & 74 & $\mathrm{CP}$ & CP 72-1372 & USA \\
\hline 21 & GT & GT97-40 & GXSRI/China & 75 & $\mathrm{CP}$ & СР 73-1547 & USA \\
\hline 22 & $\mathrm{YZ}$ & YG24 & GZSRI/China & 76 & $\mathrm{CP}$ & СР 76-1133 & USA \\
\hline 23 & $\mathrm{YZ}$ & YG26 & GZSRI/China & 77 & $\mathrm{CP}$ & СР 78-1247 & USA \\
\hline 24 & MT & MT96-1027 & FJSRI/China & 78 & $\mathrm{CP}$ & СР 84-1198 & USA \\
\hline 25 & $\mathrm{YZ}$ & YZ03-332 & YNSRI/China & 79 & $\mathrm{CP}$ & LCP 85-384 & USA \\
\hline 26 & $\mathrm{YZ}$ & YZ03-194 & YNSRI/China & 80 & $\mathrm{CP}$ & CP 89-1509 & USA \\
\hline 27 & FN & FN04-3504 & FAFUSRI/China & 81 & ROC & $\mathrm{ROC1}$ & TWSRI/China \\
\hline 28 & FN & FN04-2816 & FAFUSRI/China & 82 & ROC & ROC10 & TWSRI/China \\
\hline 29 & ROC & ROC22 & TWSRI/China & 83 & ROC & ROC20 & TWSRI/China \\
\hline 30 & $\mathrm{YT}$ & YG18 & GZSRI/China & 84 & ROC & ROC24 & TWSRI/China \\
\hline 31 & $\mathrm{YT}$ & YG16 & GZSRI/China & 85 & $\mathrm{ROC}$ & ROC25 & TWSRI/China \\
\hline 32 & MT & MT86-05 & FJSRI/China & 86 & $\mathrm{Co}$ & NCo310 & India \\
\hline 33 & MT & MT95-261 & FJSRI/China & 87 & Co & NCo376 & India \\
\hline 34 & MT & MT96-6016 & FJSRI/China & 88 & $\mathrm{Q}$ & Q127 & Australia \\
\hline 35 & FN & FN02-3924 & FAFUSRI/China & 89 & $\mathrm{Q}$ & Q162 & Australia \\
\hline 36 & FN & FN99-20169 & FAFUSRI/China & 90 & Co & Co223 & India \\
\hline 37 & GT & GY6 & GXSRI/China & 91 & Co & Co664 & India \\
\hline 38 & GT & GF98-296 & GXSRI/China & 92 & $\mathrm{CP}$ & СР 86-1180 & USA \\
\hline 39 & $\mathrm{YZ}$ & YZ99-91 & YNSRI/China & 93 & $\mathrm{YT}$ & ZZ90-45 & GZSRI/China \\
\hline 40 & Brazil & RB76-5418 & Brazil & 94 & Others & YN73-204 & GDSRI/China \\
\hline 41 & Others & GN99-591 & JXSRI/China & 95 & Others & YN91-600 & GDSRI/China \\
\hline 42 & ROC & ROC16 & TWSRI/China & 96 & YT & YT96-794 & GZSRI/China \\
\hline 43 & FN & FN11 & FAFUSRI/China & 97 & YT & YT96-853 & GZSRI/China \\
\hline 44 & FN & FN13 & FAFUSRI/China & 98 & GT & GT86-267 & GXSRI/China \\
\hline
\end{tabular}


TABLE 1: Continued.

\begin{tabular}{|c|c|c|c|c|c|c|c|}
\hline Code & Series & Accession & $\begin{array}{l}\text { Institute/country } \\
\text { Collection place }\end{array}$ & Code & Series & Accession & Institute/country \\
\hline 45 & FN & FN15 & FAFUSRI/China & 99 & GT & GT11 & GXSRI/China \\
\hline 46 & $\mathrm{FN}$ & FN16 & FAFUSRI/China & 100 & Others & CZ19 & SCSRI/China \\
\hline 47 & FN & FN22 & FAFUSRI/China & 101 & Brazil & RB72-454 & Brazil \\
\hline 48 & FN & FN23 & FAFUSRI/China & 102 & Others & FR93-244 & France \\
\hline 49 & FN & FN24 & FAFUSRI/China & 103 & Others & M63-39 & USA \\
\hline 50 & FN & FN36 & FAFUSRI/China & 104 & Others & My53-174 & Cuba \\
\hline 51 & $\mathrm{FN}$ & FN39 & FAFUSRI/China & 105 & Others & US $87-1036$ & USA \\
\hline 52 & $\mathrm{FN}$ & FN05-0644 & FAFUSRI/China & 106 & $\mathrm{CP}$ & НоСР02-623 02-623 & USA \\
\hline 53 & $\mathrm{FN}$ & FN05-1419 & FAFUSRI/China & 107 & Others & IRK67-1 & USA \\
\hline 54 & $\mathrm{FN}$ & FN05-1611 & FAFUSRI/China & & & & \\
\hline
\end{tabular}

Notes: FAFUSRI: Sugarcane Research Institute, Fujian Agriculture and Forestry University; FJSRI: Sugarcane Research Institute, Fujian Academy of Agricultural Sciences; GXSRI: Sugarcane Research Institute, Guangxi Academy of Agricultural Sciences; GZSRI: Sugarcane Research Institute, Guangzhou; GDSRI: Sugarcane Research Institute, Guangdong Academy of Agricultural Sciences; YNSRI: Sugarcane Research Institute, Yunnan Academy of Agricultural Sciences; JXSRI: Sugarcane Research Institute, Jiangxi Province; TWSRI: Sugarcane Research Institute, Taiwan.

TABLE 2: Nucleotide sequence and amplification efficiency of 20 sugarcane SCoT primers.

\begin{tabular}{|c|c|c|c|c|c|c|c|}
\hline Number & Primer & Sequence $\left(5^{\prime}-3^{\prime}\right)$ & GC (\%) & NTB & NPB & PPB & PIC \\
\hline 1 & P1 & CAACAATGGCTACCACCA & 50 & 11 & 10 & 90.91 & 0.895 \\
\hline 2 & P3 & CAACAATGGCTACCACCG & 56 & 10 & 8 & 80.00 & 0.892 \\
\hline 3 & P6 & CAACAATGGCTACCACGC & 56 & 9 & 9 & 100.0 & 0.884 \\
\hline 4 & P8 & CAACAATGGCTACCACGT & 50 & 8 & 8 & 100.0 & 0.842 \\
\hline 5 & P11 & AAGCAATGGCTACCACCA & 50 & 10 & 9 & 90.00 & 0.887 \\
\hline 6 & $\mathrm{P} 12$ & ACGACATGGCGACCAACG & 61 & 9 & 8 & 88.89 & 0.864 \\
\hline 7 & $\mathrm{P} 15$ & ACGACATGGCGACCGCGA & 67 & 8 & 7 & 87.50 & 0.854 \\
\hline 8 & P17 & ACCATGGCTACCACCGAG & 61 & 9 & 9 & 100.0 & 0.875 \\
\hline 9 & P22 & AACCATGGCTACCACCAC & 56 & 8 & 7 & 87.50 & 0.867 \\
\hline 10 & $\mathrm{P} 23$ & CACCATGGCTACCACCAG & 61 & 9 & 9 & 100.0 & 0.886 \\
\hline 11 & P25 & ACCATGGCTACCACCGGG & 67 & 9 & 8 & 88.89 & 0.834 \\
\hline 12 & P26 & ACCATGGCTACCACCGTC & 61 & 7 & 6 & 85.71 & 0.840 \\
\hline 13 & P27 & ACCATGGCTACCACCGTG & 61 & 9 & 9 & 100.0 & 0.884 \\
\hline 14 & P28 & CCATGGCTACCACCGCCA & 67 & 5 & 5 & 100.0 & 0.790 \\
\hline 15 & P29 & CCATGGCTACCACCGGCC & 72 & 11 & 10 & 90.91 & 0.892 \\
\hline 16 & $\mathrm{P} 31$ & CCATGGCTACCACCGCCT & 67 & 11 & 10 & 90.91 & 0.907 \\
\hline 17 & P32 & CCATGGCTACCACCGCAC & 67 & 6 & 6 & 100.0 & 0.806 \\
\hline 18 & P35 & CATGGCTACCACCGGCCC & 72 & 7 & 6 & 85.71 & 0.783 \\
\hline 19 & P37 & ACGACATGGCGACCAGCG & 66 & 10 & 9 & 90.00 & 0.859 \\
\hline \multirow[t]{3}{*}{20} & P39 & AACCATGGCTACCACCGC & 61 & 10 & 10 & 100.0 & 0.882 \\
\hline & Subtotal & & & 176 & 163 & & \\
\hline & Average & & & & & 92.85 & 0.861 \\
\hline
\end{tabular}

Notes: NTB: number of total bands; NPB: number of polymorphic bands; PPB: percentage of polymorphic bands; PIC: polymorphism information content.

primer. Primers P28 and P32 amplified the least number of DNA fragments of six and five, respectively. The PPB value of each primer ranged from $80.00 \%$ to $100.00 \%$, with an average of 92.85\%. Eight primers, including P28 and P32, amplified $100.00 \%$ polymorphic bands. Primers P1, P29, and P31 had an average PPB value of $90.91 \%$. Overall, the PIC values of these 20 SCoT primers ranged from 0.78 to 0.91 with an average of 0.86 . Primer P31 was the most discriminatory with a PIC value of 0.91 , whereas P35 had the lowest PIC value of 0.78 .
Since the PIC values reflected the differentiation ability of the primer, these 20 SCoT primers were able to effectively differentiate among the 107 sugarcane accessions.

3.2. Genetic Similarity. Pairwise genetic similarity coefficients among the 107 accessions ranged from 0.375 to 0.881 . The highest genetic similarity coefficient value of 0.881 was found between Q162 and ROC1. Q162 was an introduction from Australia and $\mathrm{ROCl}$ was from Taiwan. The pairwise 
genetic similarity coefficients among the six leading sugarcane accessions in China, namely, ROC10, ROC16, ROC20, ROC22, ROC25, and FN11, ranged from 0.432 to 0.767. Similarity coefficient was 0.449 between ROC10 and ROC16, 0.445 between ROC10 and ROC22, and 0.722 between ROC16 and ROC22, respectively. For the 22 newly released sugarcane accessions from the Chinese National Yield Trials Program, pairwise genetic similarity coefficients ranged from 0.398 to 0.830 . The least genetic similarity coefficient of 0.398 was found between MT96-1027 and YT96-853. The pairwise genetic similarity coefficients among the four new accessions, namely, GT97-40, FN15, YG18, and FN02-3924, ranged from 0.489 to 0.761 , with an average of 0.681 . Lastly, the pairwise genetic similarity coefficient was 0.767 between full sibs CP72-1210 and CP72-1372, 0.795 between full sibs NCo376 and NCo310, and 0.807 between full sibs YG24 and YG26, respectively.

3.3. Cluster Analysis. A homology tree is shown in Figure 1. At the genetic similarity coefficient of 0.674 , the 107 accessions were divided into six clusters, with some clusters further divided into subclusters. The Q-series accessions introduced from Australia were grouped in Cluster I. All members of Subcluster I-I were from the FY-series accessions introduced from Australia. Nonetheless, two Australian accessions were grouped in Clusters IV (Q127) and V (Q162), respectively, indicating that both were genetically distinct from the other introduced Q-series accessions. The four MT-series accessions released by the Sugarcane Research Institute of Fujian Academy of Agriculture Sciences were grouped in Subcluster I-II. Two YZ-series accessions, YZ03-332 (ROC1 × GT73$167)$ and YZ03-194 (ROC $25 \times$ YT 97-20), were also placed in Subcluster I-II. However, YZ99-91 (ROC10 × YC84/125), another YZ-series accession, was grouped in Cluster II, probably due to the fact that YZ99-91 had totally different parents from those of YZ03-194 and YZ03-332.

Of the YG-series accessions, YG16 (YN73-204 × CP861633) and YG18 (YN73-204 × CP72-1210) shared the same female parent (YN73-204). The similarity coefficients were 0.511 between YG16 and YN73-204 and 0.449 between YG18 and YN73-204, causing YG16 and YG18 to be placed in different cluster (Cluster I) from the female parent YN73204 (Cluster VI). Since the mid-1980s, the "ROC"-series accessions have been one of the most important sources of parental materials for the sugarcane breeding programs on Mainland China. The pairwise genetic similarity coefficients among ROC1, ROC10, ROC20, ROC24, and ROC25 were all high, resulting in the grouping of these "ROC"-series accessions in Cluster IV. However, two other "ROC"-series accessions, namely, ROC22 and ROC16, which along with ROC10 had been grown in the largest planting areas on Mainland China in the recent 25 years, were placed into Clusters I and II, respectively. The four "India"-series accessions were placed in Subclusters IV-II. The three "Brazil"-series accessions were placed into Cluster I (CI-2003), Cluster II (RB76-5418), and Cluster VI (RB72-454), respectively. The pairwise genetic similarity coefficient was 0.648 between CI20030 and RB76-5418, 0.420 between CI-2003 and RB72-454, and 0.545 between RB72-454 and RB76-5418, respectively, indicating a high genetic diversity among the three Brazilian accessions.

3.4. Principal Component Analysis. Principal component analyses divided the 107 accessions into two distinct groups (Figure 2): the Foreign Group and the Domestic Group. In the Foreign Group, the "CP"-series accessions are introduced from the USA. Although the "YC"-series accessions were developed by the Guangzhou Industrial Sugar Research Institute, most parental clones of these "YC"-series accessions were "CP"-series accessions. The "ROC"-series accessions were introduced from Taiwan. The "Indian"-series accessions and most of the "Other"-series accessions were introduced from other foreign countries. In the Domestic Group, both the "FN"- and "MT"-series accessions were released by the two sugarcane breeding programs in Fujian Province, one at the Fujian Agriculture and Forestry University and the other at the Fujian Academy of Agricultural Sciences. The "GT"-, "YT"-, and "YZ"-series accessions were released from the sugarcane breeding institutes in Guangxi, Guangdong, and Yunnan Provinces, respectively. There was a large difference in genetic basis between the Foreign Group and the Domestic Group (Figure 2). Therefore, the PCA results suggested that it would be important to combine both foreign and domestic germplasm accessions for the improvement of sugarcane genetic diversity in Chinese sugarcane breeding programs.

\subsection{Genetic Diversity within the Local Sugarcane Germplasm} Collection. The number of SCoT polymorphic bands (NPB) varied from 74 to 164 across the 12 series of sugarcane accessions (Table 3). The highest NPB value (164) was found in the "Other"-series. The "Q"-series ranked the second to the highest. The "CP"- and "ROC"-series had similar numbers of polymorphic bands. The least number of polymorphic bands of 74 was observed in the "YZ"-series, which also had the lowest PPB value. The "Co"-series had the second lowest $\mathrm{PPB}$ value (43.75\%). The extent of variability among NPB, $\mathrm{PPB}, \mathrm{Na}, \mathrm{Ne}, h$, and $I$ indices also indicated a high level of genetic diversity among the 12 series (Table 3 ). The $\mathrm{Na}$ values of these 12 series ranged from 1.4205 to 1.9318 , while the $\mathrm{Ne}$ values ranged from 1.2844 to 1.6440 . The observed percentages of effective alleles were from 1.2844 to 1.6440 . The "YZ"-series had the lowest observed percentage of effective alleles of 1.2844. These results suggested that the 20 SCoT primers had high amplification efficiencies and thus could be an effective method for the genetic diversity analysis of sugarcane germplasm collections.

The genetic diversity index $h$ reflected the diversity and differentiation among the germplasm collections. Shannon's index $I$ was used to evaluate the genetic diversity within and between the series. The higher the index, the higher the genetic diversity. The $h$ values of these 12 series were from 0.1635 to 0.3619 . Shannon's index $(I)$ varied from 0.2411 to 0.5298 . The "Other"-series had the highest $h(0.3619)$ and the highest $I(0.5298)$ values, because the 10 accessions were from different breeding institutes in other countries. Therefore, the genetic distances among accessions within the "Other"series were farther and the differences in their genetic basis were larger. If different accessions within the same series were 


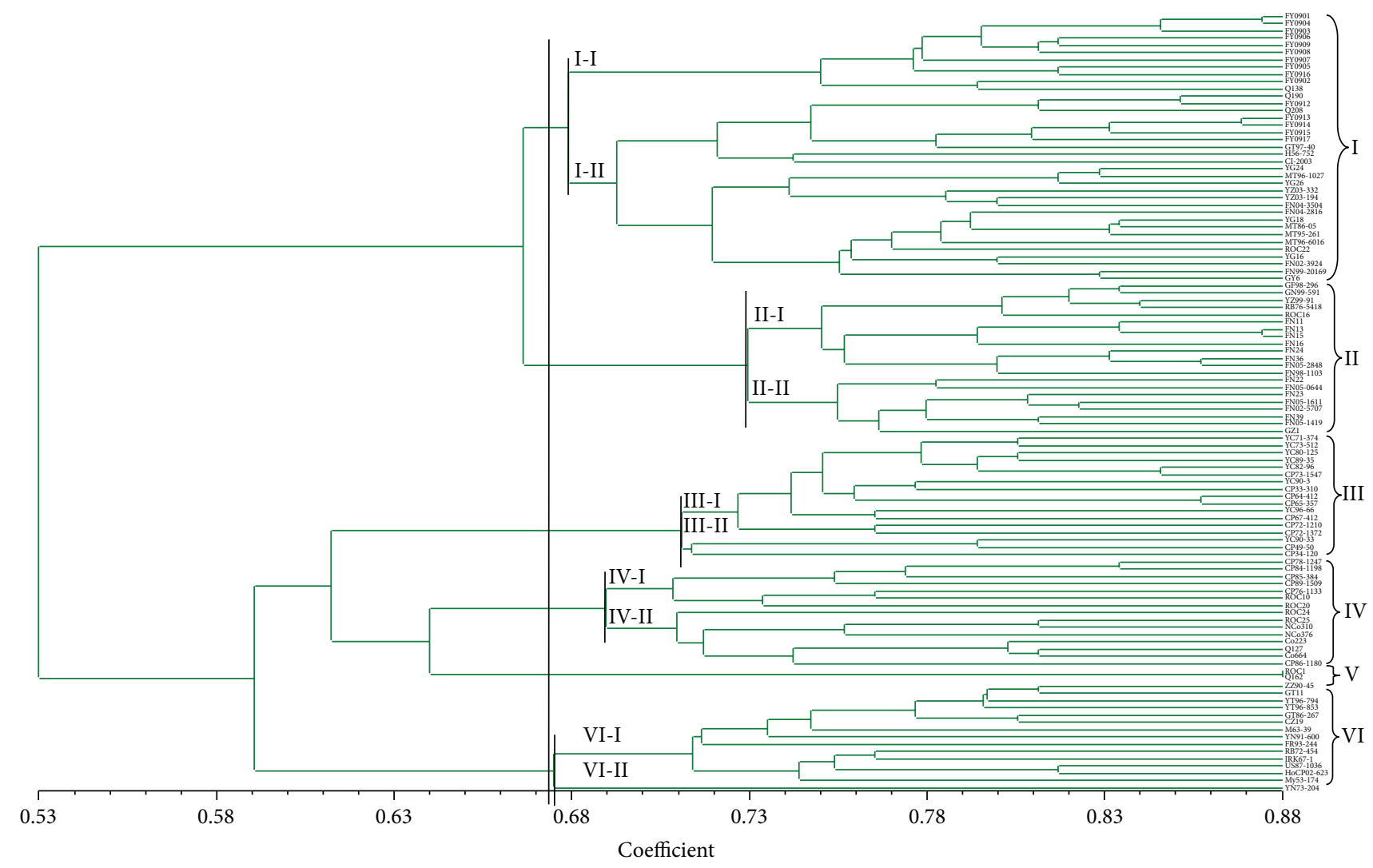

FIgURE 1: Cluster analysis dendrogram of 107 accessions from a local sugarcane germplasm collection based on SCoT marker data.

TABLE 3: Genetic diversity of 107 sugarcane accessions based on SCoT marker data.

\begin{tabular}{lcccccccc}
\hline Number & Series name & Clones & NPB & PPB & Na & Ne & h \\
\hline 1 & CP & 16 & 159 & 90.34 & 1.9034 & 1.6075 & 0.3466 & 0.5099 \\
2 & FN & 20 & 123 & 69.89 & 1.6989 & 1.4074 & 0.2371 \\
3 & MT & 4 & 85 & 48.30 & 1.4830 & 1.3099 & 0.1785 \\
4 & YC & 8 & 100 & 56.82 & 1.5682 & 1.3876 & 0.2185 & 0.3554 \\
5 & YZ & 3 & 74 & 42.05 & 1.4205 & 1.2844 & 0.1635 \\
6 & Co & 4 & 77 & 43.75 & 1.4375 & 1.3436 & 0.1880 \\
7 & Brazil & 3 & 122 & 69.32 & 1.6932 & 1.4518 & 0.2634 \\
8 & ROC & 7 & 158 & 89.77 & 1.8977 & 1.6204 & 0.3496 \\
9 & Q & 20 & 160 & 90.91 & 1.9091 & 1.4646 & 0.2725 \\
10 & GT & 5 & 135 & 76.70 & 1.7670 & 1.4636 & 0.2710 \\
11 & YT & 7 & 144 & 81.82 & 1.8182 & 1.4951 & 0.5122 \\
12 & Others & 10 & 164 & 93.18 & 1.9318 & 1.6440 & 0.4144 \\
\hline
\end{tabular}

Notes: NPB: number of polymorphic bands; PPB: percentage of polymorphic bands; Na: observed number of alleles; Ne: effective number of alleles; $h$ : Nei's genetic diversity; $I$ : Shannon's information index.

crossed, one would expect a higher genetic diversity among the cross-progeny. The $h$ and $I$ values of the "ROC"-series were 0.3496 and 0.5122 , respectively, which were similar to those of the "CP"-series. The "CP"- and "ROC"-series had high genetic diversity, ranking the second and the third after the "Other"-series. Lower genetic diversity and Shannon's index were observed within both the "MT"-series ( 0.1785 and $0.2654)$ and "YZ"-series (0.1635 and 0.2411).
Since the "Other"-series accessions were from different breeding institutes of countries other than China, the genetic diversity among accessions of the "Other"-series was not compared in this study. However, the genetic diversity among the remaining 11 series was analyzed. The NPB and PPB were 175 and $99.43 \%$ for the 11 series, which were higher than those within any series, including the "Other"-series (Table 3). The percentage of effective alleles was 1.6183, similar 


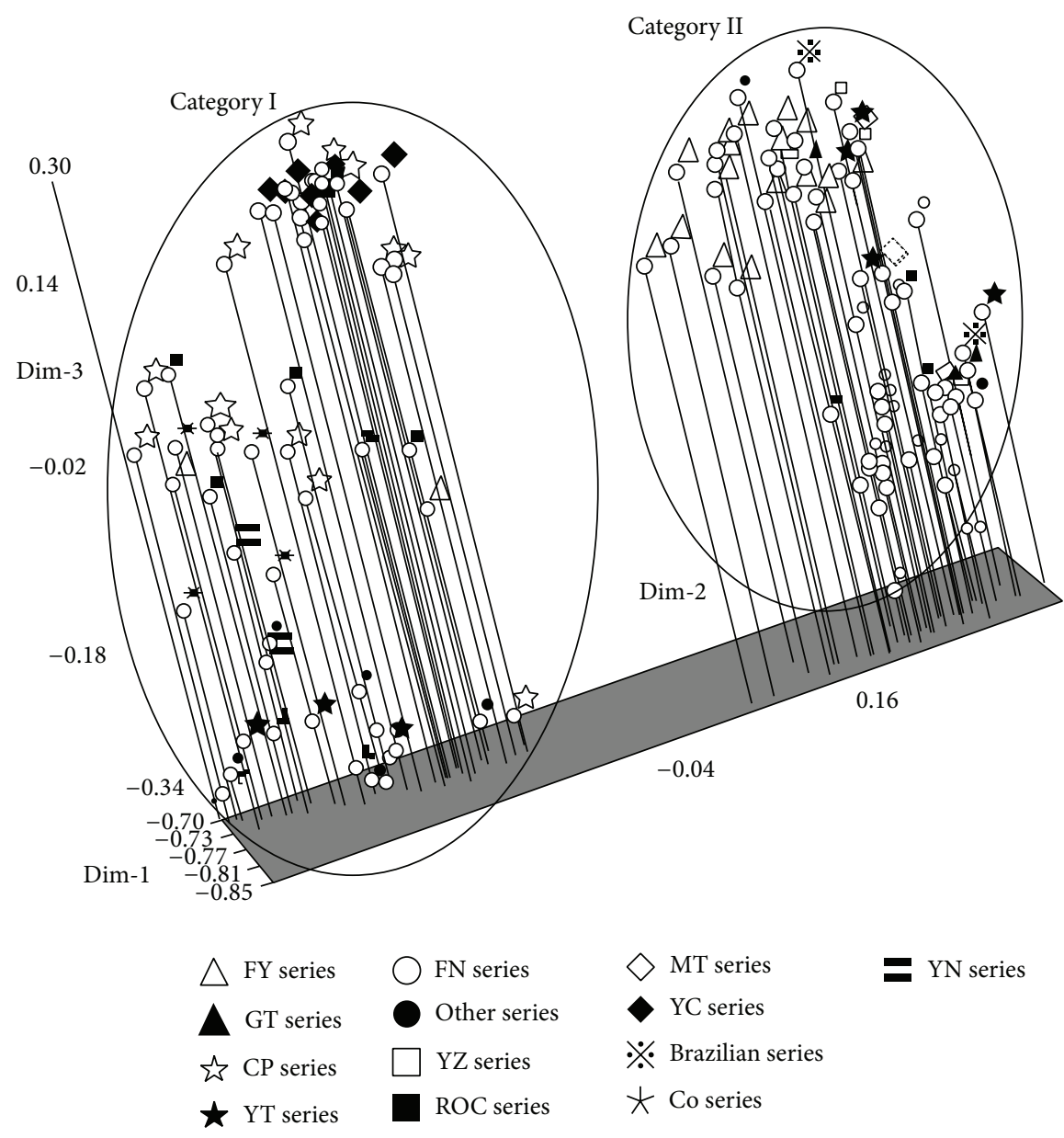

FIgURE 2: Principal component analysis of 107 accessions from a local sugarcane germplasm collection based on SCoT marker data.

to that within each series. The $h$ value $(0.3592)$ and $I$ value (0.5343) were significantly higher than those of any series except the "Other"-series. The results indicated that the selection of cross-parents released from different breeding institutes would be beneficial in developing new sugarcane cultivars because of higher genetic diversity. The total genetic diversity index $(H t)(0.3640)$ among the 107 accessions was not only higher than between series (0.3592), but higher than within series $H s(0.2526)$ as well. The genetic differentiation coefficient $\left(G_{\text {st }}\right)$ between series was 0.3060 , and the gene flow $\left(N_{m}\right)$ was 1.1340 , indicating that gene flow and genetic differentiation occurred between the series as well.

\section{Discussion and Conclusions}

Improvement of sugarcane through genetic manipulation based on sexual crossing has been a directed, ongoing process since 1888 [5]. However, conventional breeding technology generally takes 12 to 15 years to develop a sugarcane cultivar with the first selection cycle on about 0.3 million seedlings. Because sugarcane is a clonally propagated crop, creation of new genotypes is only done through sexual crossing. The seedling and ratoon crops of new genotypes are subjected to several cycles of evaluation and selection under various environments in comparison to concurrent elite cultivars as checks [1]. Choosing parental accessions is the most crucial step in any sugarcane improvement program. There has never been single incidence of developing a sugarcane cultivar out of a poor cross $[1,5-7]$. Therefore, genetic diversity analysis of sugarcane germplasm based on molecular evaluation and characterization is the basis for effective germplasm utilization. A high genetic diversity and complementarity between two parental accessions are crucial for producing high quality seedling populations of hybrid progeny $[1,4-7]$.

SCOT is a new gene-targeted technique based on the nucleotide sequences at the translational start site ATG. The technique has been validated in several plant species [32-41, 47]. In this study, the utility of 20 SCoT primers was explored through evaluation of genetic polymorphism among 107 accessions of a local sugarcane germplasm collection. The percentage of polymorphic bands (PPB) detected reached $92.85 \%$. The polymorphic information content (PIC) values of these SCoT bands ranged from 0.783 to 0.907 with an average of 0.861 , which was much higher than that of the SSR markers (0.57) reported by Filho et al. [48]. The average observed percentage of effective alleles was $85.49 \%$, indicating the highly polymorphic and robust nature of these SCoT markers. 
One of the modern sugarcane breeding objectives is to broaden the genetic basis of cultivars [1]. Genetic similarity analyses in sugarcane suggested that cross-progeny from the same parental combination could display large genetic differences due to the complex polyploid genome of sugarcane $[1,6$, 7], which was the basis for seedling selection [1-3]. UPGMA clustering and principal component analyses of the SCoT marker data indicated that the extent of genetic diversity among the three most popular "ROC" accessions in China, namely, ROC22, ROC16, and ROC10, was relatively high. The average genetic similarity coefficient among the 22 newly released accessions from the Chinese National Yield Trials Program was only 0.593 , indicating a fairly abundant genetic diversity among these accessions. The principal component analysis divided the 107 sugarcane accessions into distinct domestic and foreign groups. Crossing between domestically bred sugarcane accessions with foreign introductions may help enhance the genetic diversity level of sugarcane germplasm in China.

Based on the geographic origin, the 107 sugarcane accessions were sorted into 12 series, namely, "Brazil"-, "CP"-, "FN"-, "GT"-, "India"-, "MT"-, “Q”-, "ROC”-, "YC"-, “YT”-, "YZ"-, and "Other"-series. The "Other"-series included 10 accessions that belonged to miscellaneous breeding institutes. The genetic diversity $(h)$ indices among these 12 series ranged from 0.1635 to 0.3619 . The highest $h$ value was found in "Other-series" (0.3619), followed by ROC- (0.3496) and CP(0.3466) series, respectively. The lowest $h$ value existed in the YZ-series (0.1635). It was noteworthy that the genetic diversity between any two series was much greater than among the accessions within the same series. A previous report concluded that a gene flow index of $N_{m}>1$ would be indicative of no significant differentiation among populations [49]. The gene flow index was moderate $\left(N_{m}=1.1340\right)$, indicating a high level of genetic diversity within populations that were not prone to genetic drift. The mode of pollen dispersal, which determined the gene flow among populations, might partly account for this moderate differentiation [1]. This was further confirmed by the low level of interpopulation genetic differentiation manifested by the low gene differentiation coefficient $\left(G_{\text {st }}\right)$ among populations $(0.3060)$. Therefore, we deduced that the genetic diversity among the 107 accessions had existed mainly between different series.

From all the above, the knowledge of genetic diversity among the local sugarcane germplasm collection would help direct future sugarcane cross-breeding programs in China. It would also provide foundation data for managing sugarcane germplasm resources, including the construction of a core collection and regional variety distribution and subrogation.

\section{Conflict of Interests}

The authors declare that there is no conflict of interests regarding the publication of this paper.

\section{Acknowledgments}

This work was supported by the earmarked fund for the Modern Agriculture Technology of China (CARS-20) and the 948 Program on the Introduction of International Advanced Agricultural Science and Technique of Department of Agriculture (2014-S18). The authors especially thank Andrew C. Allan in The New Zealand Institute for Plant \& Food Research Ltd. (Plant and Food Research), Mt Albert Research Centre, Auckland, New Zealand, for his valuable comments and support during paper preparation.

\section{References}

[1] R. K. Chen, L. P. Xu, Y. Q. Lin et al., Modern Sugarcane Genetic Breeding, China Agriculture Press, Beijing, China, 2011.

[2] J. Luo, Z. H. Deng, Y. X. Que, Z. N. Yuan, and R. K. Chen, "Productivity and stability of sugarcane varieties in the 7th round national regional trial of China," Chinese Journal of Applied and Environmental Biology, vol. 18, no. 5, pp. 734-739, 2012.

[3] L. D. Baver, "Practical lessons from trends in Hawaiian sugar production," in Proceedings of the International Society of Sugar Cane Technology, vol. 11, pp. 68-77, 1963.

[4] R. S. Loomis and W. A. Williams, "Maximum crop productivity: an estimate," Crop Science, vol. 3, no. 1, pp. 67-72, 1963.

[5] G. C. Stevenson, Genetic and Breeding of Sugarcane, Longmans, Green, London, UK, 1965.

[6] R. Ming, P. H. Moore, K. K. Wu et al., "Sugarcane improvement through breeding and biotechnology," in Plant Breeding Reviews, J. Janick, Ed., vol. 27, pp. 15-118, John Wiley \& Sons, New York, NY, USA, 2006.

[7] P. A. Jackson, "Breeding for improved sugar content in sugarcane," Field Crops Research, vol. 92, no. 2-3, pp. 277-290, 2005.

[8] J. S. Xu, L. P. Xu, M. Q. Zhang, and R. K. Chen, "Phylogenetic relationships of Saccharum to its relative genus based on RAPD analysis," Acta Agriculturae Universitatis Jiangxiensis, vol. 25, no. 6, pp. 925-928, 2003.

[9] S. N. Sharma, A. K. Shahi, and T. N. Srivastava, "Taxonomic relationship of Cymbopogon species based on volatile leaf oil chemical constituents," Journal of Economic and Taxonomic Botany, vol. 24, no. 1, pp. 115-122, 2000.

[10] R. S. Sangwan, A. H. A. Farooqi, R. P. Bansal, and N. Singh-Sangwan, "Interspecific variation in physiological and metabolic responses of five species of Cymbopogon to water stress," Journal of Plant Physiology, vol. 142, no. 5, pp. 618-622, 1993.

[11] J. H. Daugrois, L. Grivet, D. Roques et al., "A putative major gene for rust resistance linked with a RFLP marker in sugarcane cultivar 'R570"' Theoretical and Applied Genetics, vol. 92, no. 8, pp. 1059-1064, 1996.

[12] A. D’Hont, Y. H. Lu, P. Feldmann, and J. C. Glaszmann, “Cytoplasmic diversity in sugar cane revealed by heterologous probes," Sugar Cane, vol. 1, pp. 12-15, 1993.

[13] L. Grivet, A. D’Hont, D. Roques, P. Feldmann, C. Lanaud, and J. C. Glaszmann, "RFLP mapping in cultivated sugarcane (Saccharum spp.): genome organization in a highly polyploid and aneuploid interspecific hybrid," Genetics, vol. 142, no. 3, pp. 9871000, 1996.

[14] J. C. Glaszmann, Y. H. Lu, and C. Lanaud, "Variation of nuclear ribosomal DNA in sugarcane," Journal of Genetics and Breeding, vol. 44, no. 3, pp. 191-198, 1990.

[15] Y.-B. Pan, D. M. Burner, and B. L. Legendre, "An assessment of the phylogenetic relationship among sugarcane and related 
taxa based on the nucleotide sequence of 5S rRNA intergenic spacers," Genetica, vol. 108, no. 3, pp. 285-295, 2000.

[16] J. Mudge, W. R. Andersen, R. L. Kehrer, and D. J. Fairbanks, "A RAPD genetic map of Saccharum officinarum," Crop Science, vol. 36, no. 5, pp. 1362-1366, 1996.

[17] V. K. Madan, M. Bikash, M. I. Ansari et al., "RAPD-PCR analysis of molecular variability in the red rot pathogen (Collectotrichum falcatum)," Sugar Cane International, vol. 3, pp. 5-8, 2002.

[18] P. H. Chen, H. Zhang, and R. K. Chen, "Assisted selection of sugarcane parents based on RAPD technique," Molecular Plant Breeding, vol. 2, no. 5, pp. 675-681, 2004.

[19] A. L. Yu, M. Q. Zhang, and R. K. Chen, "Applicability of intersimple sequence repeat polymorphisms in sugarcane and its related genera as DNA markers," Journal of Fujian Agricultural and Forestry University (Natural Sciences), vol. 31, no. 4, pp. 484489, 2002.

[20] K. S. Aitken, P. A. Jackson, and C. L. McIntyre, "A combination of AFLP and SSR markers provides extensive map coverage and identification of homo(eo)logous linkage groups in a sugarcane cultivar," Theoretical and Applied Genetics, vol. 110, no. 5, pp. 789-801, 2005.

[21] P. Besse, G. Taylor, B. Carroll, N. Berding, D. Burner, and C. L. McIntyre, "Assessing genetic diversity in a sugarcane germplasm collection using an automated AFLP analysis," Genetica, vol. 104, no. 2, pp. 143-153, 1998.

[22] Q. Cai, Y. H. Fan, K. Aitken, G. Piperidis, C. L. McIntyre, and P. Jackson, "Assessment of the phylogenetic relationships within the "Saccharum complex" using AFLP markers," Acta Agronomica Sinica, vol. 31, no. 5, pp. 551-559, 2005.

[23] K. S. Aitken, J.-C. Li, P. Jackson, G. Piperidis, and C. L. McIntyre, "AFLP analysis of genetic diversity within Saccharum officinarum and comparison with sugarcane cultivars," Australian Journal of Agricultural Research, vol. 57, no. 11, pp. 1167-1184, 2006.

[24] X. X. Song, Genetic diversity of sugarcane and its relatives by SRAP and TRAP markers [M.S. thesis], Fujian Agriculture and Foresty University, 2009.

[25] Y. X. Que, T. S. Chen, L. P. Xu, and R. K. Chen, "Genetic diversity among key sugarcane clones revealed by TRAP markers," Journal of Agricultural Biotechnology, vol. 17, no. 3, pp. 496-503, 2009.

[26] G. M. Cordeiro, F. Eliott, C. L. McIntyre, R. E. Casu, and R. J. Henry, "Characterisation of single nucleotide polymorphisms in sugarcane ESTs," Theoretical and Applied Genetics, vol. 113, no. 2, pp. 331-343, 2006.

[27] X. D. Huang, DNA profiling and genetic diversity of sugarcane germplasms by SSR loci [M.S. thesis], Fujian Agriculture and Foresty University, 2009.

[28] Y. B. Pan, "Databasing molecular identities of sugarcane (Saccharum spp.) clones constructed with microsatellite (SSR) DNA markers," The American Journal of Plant Sciences, vol. 1, no. 2, pp. 87-94, 2010.

[29] P. Liu, Y. Que, and Y.-B. Pan, "Highly polymorphic microsatellite DNA markers for sugarcane germplasm evaluation and variety identity testing," Sugar Tech, vol. 13, no. 2, pp. 129-136, 2011.

[30] Q. You, L. P. Xu, Y. F. Zheng, and Y. X. Que, "Genetic diversity analysis of sugarcane parents in Chinese breeding programmes using gSSR markers," The Scientific World Journal, vol. 2013, Article ID 613062, 11 pages, 2013.
[31] T. G. Marconi, E. A. Costa, H. R. C. A. N. Miranda et al., "Functional markers for gene mapping and genetic diversity studies in sugarcane," BMC Research Notes, vol. 4, article 264, 2011.

[32] B. C. Y. Collard and D. J. Mackill, "Start codon targeted (SCoT) polymorphism: a simple, novel DNA marker technique for generating gene-targeted markers in plants," Plant Molecular Biology Reporter, vol. 27, no. 1, pp. 86-93, 2009.

[33] H. Chen, X. H. He, C. Luo, J. H. Zhu, and F. Li, "Analysis on the genetic diversity of 24 longan (Dimocarpus longan) accessions by SCoT markers," Acta Horticulturae Sinica, vol. 37, no. 10, pp. 1651-1654, 2010.

[34] D.-L. Guo, J.-Y. Zhang, and C.-H. Liu, "Genetic diversity in some grape varieties revealed by SCoT analyses," Molecular Biology Reports, vol. 39, no. 5, pp. 5307-5313, 2012.

[35] A. M. Gorji, P. Poczai, Z. Polgar, and J. Taller, "Efficiency of arbitrarily amplified dominant markers (SCOT, ISSR and RAPD) for diagnostic fingerprinting in tetraploid potato," The American Journal of Potato Research, vol. 88, no. 3, pp. 226-237, 2011.

[36] Q. Q. Jiang, G. Y. Long, W. W. Li, and Z. N. Deng, "Identification of genetic variation in Citrus sinensis from Hunan based on start codon targeted polymorphism," Agricultural Science and Technology, vol. 12, no. 11, pp. 1594-1599, 2011.

[37] C. Luo, X.-H. He, H. Chen, S.-J. Ou, and M.-P. Gao, "Analysis of diversity and relationships among mango cultivars using start codon targeted (SCoT) markers," Biochemical Systematics and Ecology, vol. 38, no. 6, pp. 1176-1184, 2010.

[38] C. Luo, X.-H. He, H. Chen et al., "Genetic diversity of mango cultivars estimated using SCoT and ISSR markers," Biochemical Systematics and Ecology, vol. 39, no. 4-6, pp. 676-684, 2011.

[39] C. Luo, X.-H. He, H. Chen, Y. Hu, and S.-J. Ou, "Genetic relationship and diversity of Mangifera indica L.: revealed through SCoT analysis," Genetic Resources and Crop Evolution, vol. 59, no. 7, pp. 1505-1515, 2012.

[40] F. Xiong, R. Zhong, Z. Han et al., "Start codon targeted polymorphism for evaluation of functional genetic variation and relationships in cultivated peanut (Arachis hypogaea L.) genotypes," Molecular Biology Reports, vol. 38, no. 5, pp. 3487-3494, 2011.

[41] B. Amirmoradi, R. Talebi, and E. Karami, "Comparison of genetic variation and differentiation among annual Cicer species using start codon targeted (SCoT) polymorphism, DAMD-PCR, and ISSR markers," Plant Systematics and Evolution, vol. 298, no. 9, pp. 1679-1688, 2012.

[42] S. Kwok, D. E. Kellogg, N. McKinney et al., "Effects of primertemplate mismatches on the polymerase chain reaction: human immunodeficiency virus type 1 model studies," Nucleic Acids Research, vol. 18, no. 4, pp. 999-1005, 1990.

[43] D. Botstein, R. L. White, M. Skolnick, and R. W. Davis, "Construction of a genetic linkage map in man using restriction fragment length polymorphisms," The American Journal of Human Genetics, vol. 32, no. 3, pp. 314-331, 1980.

[44] F. C. Yeh, R. C. Yang, T. B. J. Boyle, Z. H. Ye, and J. X. Mao, "POPGENE, The user friendly shareware for population genetic analysis version1. 31," University of Alberta and Centre For International Forestry Research, vol. 28, pp. 45-47, 1999.

[45] F. J. Rohlf, NTSYS-Pc Numerical Taxonomy and Multivariate Analysis System, Version 2.1. User Guide, Exeter Software, New York, NY, USA, 2000.

[46] M. Nei, "Estimation of average heterozygosity and genetic distance from a small number of individuals," Genetics, vol. 89, no. 3, pp. 583-590, 1978. 
[47] S. Mulpuri, T. Muddanuru, and G. Francis, "Start codon targeted (SCoT) polymorphism in toxic and non-toxic accessions of Jatropha curcas L. and development of a codominant SCAR marker," Plant Science, vol. 207, pp. 117-127, 2013.

[48] L. S. C. D. Filho, P. P. Silva, J. M. Santos et al., "Genetic similarity among genotypes of sugarcane estimated by SSR and coefficient of parentage," Sugar Tech, vol. 12, no. 2, pp. 145-149, 2010.

[49] M. Slatkin, "Gene flow in natural populations," Annual Review of Ecology and Systematics, vol. 16, pp. 393-430, 1985. 

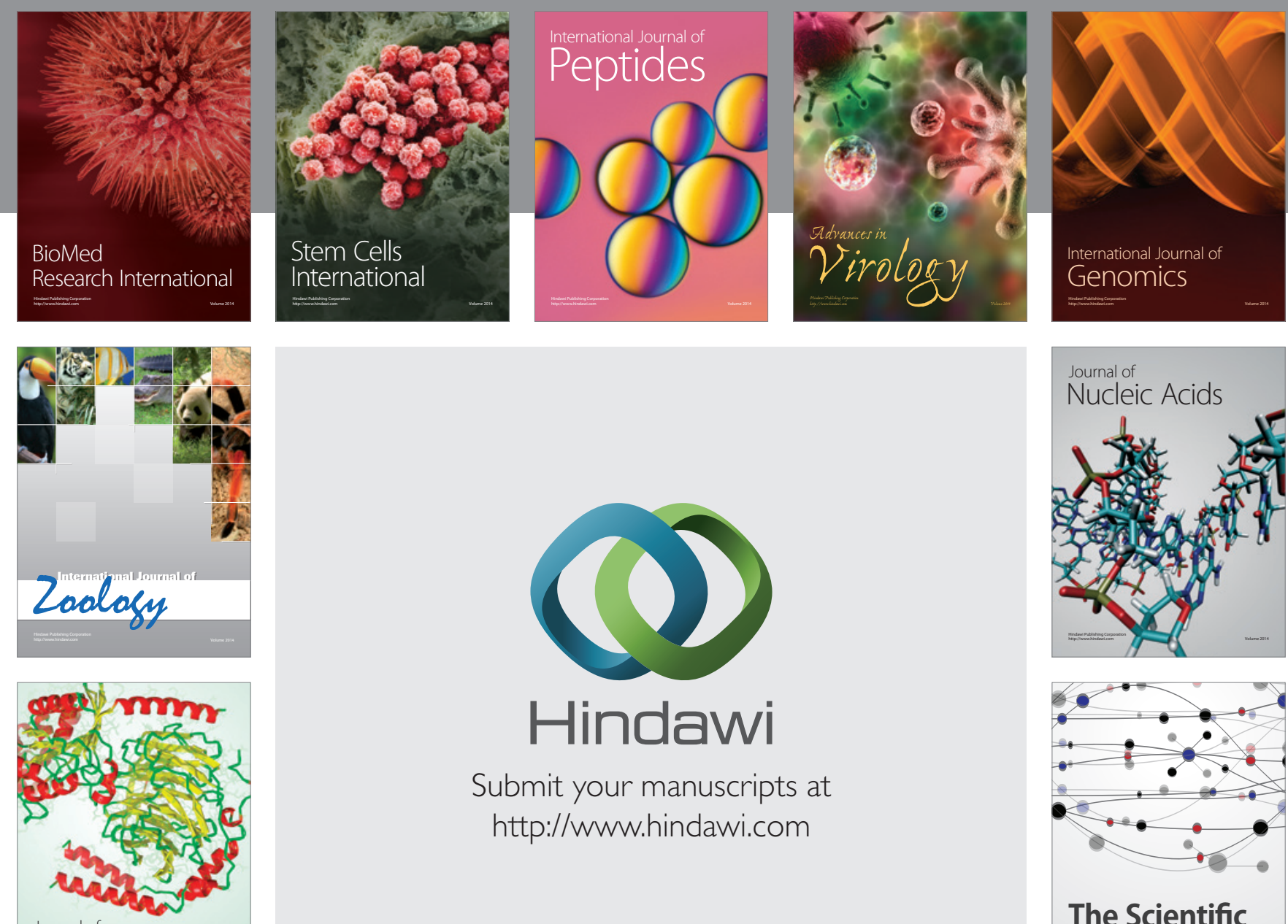

Submit your manuscripts at

http://www.hindawi.com

Journal of
Signal Transduction
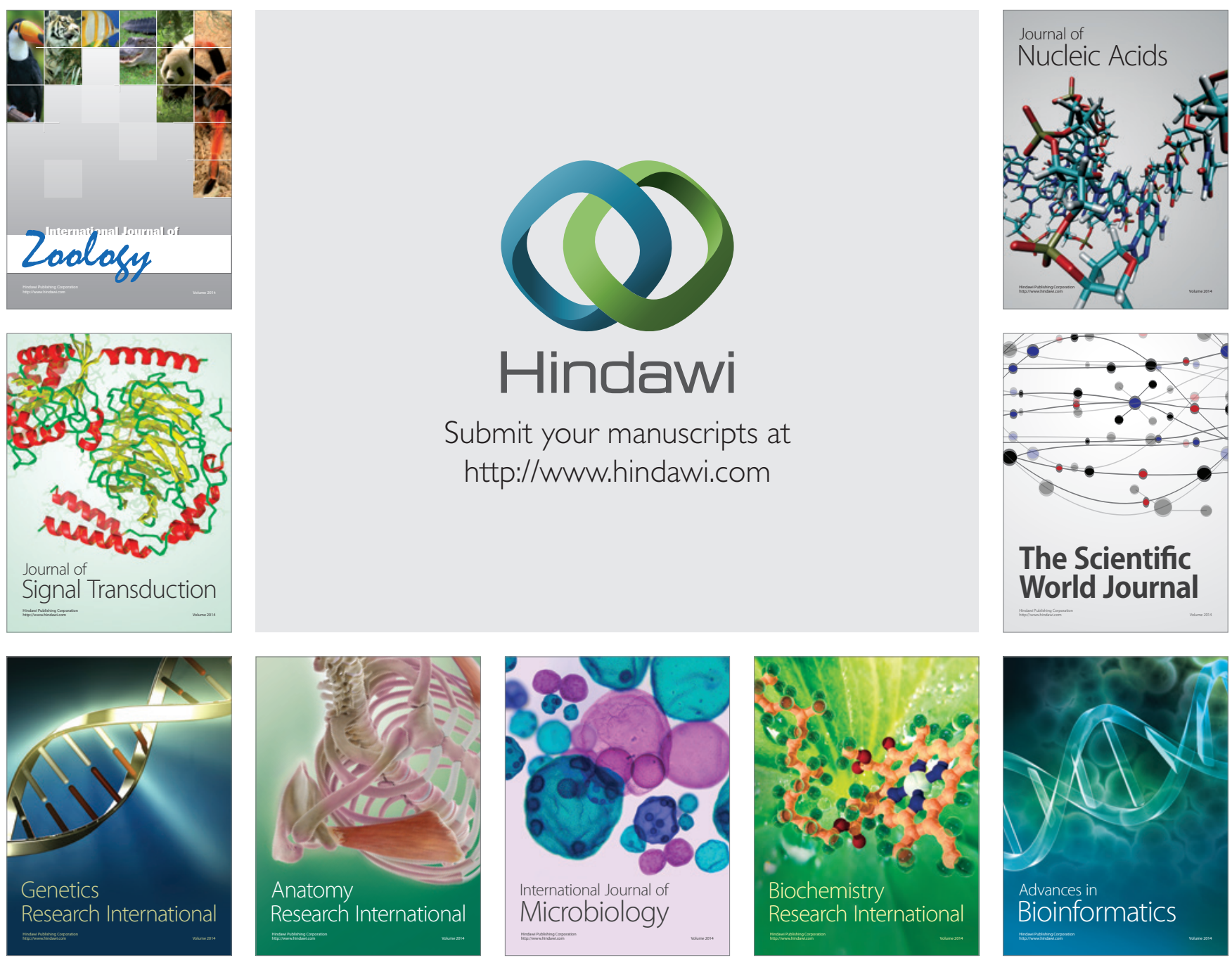

The Scientific World Journal
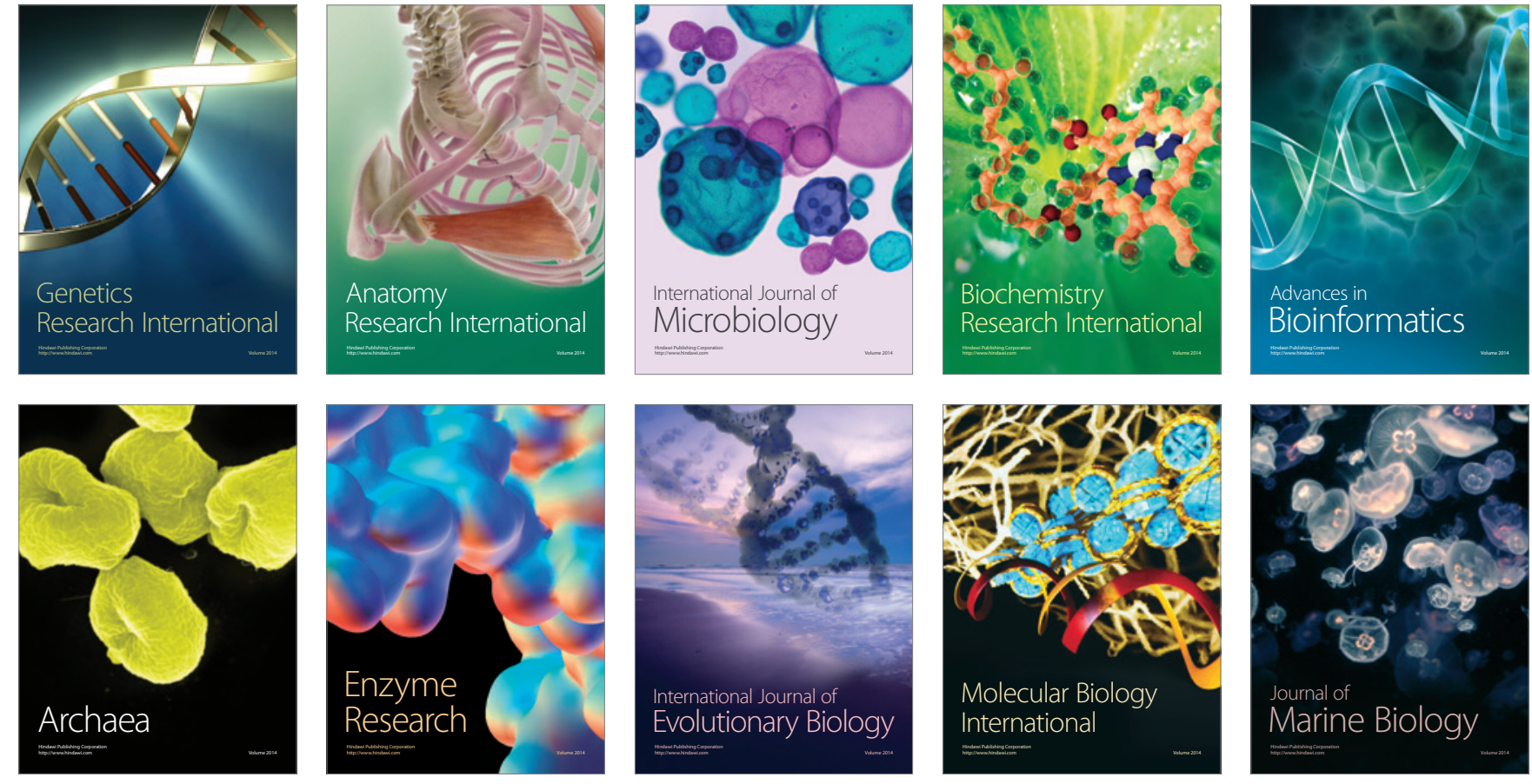